\title{
Obtaining and properties of active charcoal from pyrolized wood waste
}

\author{
$\underline{\text { Anton Kuzmin }}^{1}$, Oleg Kuzmin ${ }^{1}$, Tetyana Shendrik ${ }^{2}$ \\ 1 - National University of Food Technologies, UKRAINE, Kyiv, Volodymyrska str., 68, \\ E-mail:kuzmin_ovl@nuft.edu.ua
}

2 - L.M. Litvinenko Institute of Physical-Organic Chemistry and Coal Chemistry of NAS, UKRAINE, Kyiv, 50 Kharkivske shosse, E-mail: shendriktg@gmail.com

\begin{abstract}
Activated carbon (AB) with a high yield, developed specific surface (mainly with micropores) was obtained by the method of alkaline activation of pyrolyzed wood waste from the smoking industry (carbonized chips (CC). Their high sorption capacity toward phenol, lead ions and dye - methylene blue (MB)wass determined.
\end{abstract}

Keywords - waste of smoke production, alkaline activation, surface, sorption, pollutants

\section{Introduction}

The search for economically feasible ways to obtain cheap sorption materials to clean contaminated environments remains an urgent problem for the whole world. Among such materials, a significant place is occupied by carbon sorbents, the raw material for which there is a wide range of precursors (natural coal, peat, wood, carbon waste of different genesis). But only $2 \%$ of various types of waste are used for the production of sorbents, although the reserves are very large. For solving special problems of alcoholic beverage production (LBP) it is important to obtain activated carcoal (AC) with certain properties from available renewable raw materials

The real prospective raw material for the manufacture of such sorption materials may be wood waste from the smoke industry. They are formed during the pyrolysis of woody chips as hard-core rocks (beech, alder, oak, elm, linden, maple, etc.), and wood pecker chips (cherry, cherry, apple, apricot, plum). The purpose of our work was to evaluate the properties of potential sorbents, obtained from technological waste of the food industry. They must be suitable for cleaning various environments, including water-alcohol raw materials.

\section{Experimental}

The wood waste obtained with smoking of food products (humidity $\mathrm{W}_{1}=67-82 \%$ was dried in air $\left(\mathrm{T}_{1}=293-298 \mathrm{~K}\right)$ during $\tau_{1}=(336-504) \cdot 60^{2} \mathrm{sec}$, then dried at a temperature $\mathrm{T}_{2}=373-383 \mathrm{~K}$ to an air-dry state with humidity $\mathrm{W}_{2}=4-8 \%$. As an activating agent, potassium hydroxide $(\mathrm{KOH})$ was used which was injected by $\mathrm{CC}$ impregnation with an aqueous solution of $\mathrm{KOH}$ and maintained for $\tau_{9}=(18-24) \cdot 60^{2} \mathrm{sec}$ at $\mathrm{T}_{8}=291-295 \mathrm{~K}$, then dried at $\mathrm{T}_{9}=373-383 \mathrm{~K}$ to moisture content $\mathrm{W}_{10}=4-8 \%$. Then the blend was activated in an argon current with volumetric flow rates - $\mathrm{Q} \leq 5.6 \cdot 10-7 \mathrm{~m}^{3} / \mathrm{s}$ at non-isothermal heating of $0.07 \mathrm{deg} / \mathrm{s}$ to $\mathrm{T}_{10}=873-1073 \mathrm{~K}[1]$.

The conditions for obtaining AC from CC and some product characteristics are given in the table in comparison with those for charcoal sorbents, obtained from lignite. It can be seen that the sorbents from the carbonized wood waste have better some indexes, then tested samples. These are the consumption of the activating agent, the product yield and sorption activity toward some pollutants. The comparison of the distribution of pores in the sorbent from lignite and in the AC from the waste smoke production is shown in the figure. The CC sorbent is predominantly microporous, which makes it promising for use in a wide range of processes.

The best result on the quality of the vodka according to the results of the findings of 3 professional tasters was set for $\mathrm{AB}$ from waste of smoke production, activated alkaline. Estimates of the vodka purified by it were 9,68-9,70 against 9,4-9,6 for the initial sorting and after purification with the sorbent, obtained from CC, activated by orthophosphoric acid [2]. 
Table 1. Conditions of obtaining an AC and its characteristics

\begin{tabular}{|c|c|c|c|c|c|c|}
\hline Index & $\begin{array}{l}\text { Units of } \\
\text { measurement }\end{array}$ & Title of index & \multicolumn{2}{|c|}{ AC from lignite } & \multicolumn{2}{|c|}{$\mathrm{AB}$ from $\mathrm{CC}$} \\
\hline \multicolumn{3}{|c|}{ Activation temperature, $\mathrm{K}$} & \multicolumn{2}{|l|}{1073} & \multicolumn{2}{|l|}{1073} \\
\hline \multicolumn{3}{|c|}{ State of activating agent $\mathrm{KOH}$} & \multicolumn{2}{|c|}{ solid } & \multicolumn{2}{|c|}{$50 \%$-solution } \\
\hline \multicolumn{3}{|c|}{ Raw material / agent, kg / kg } & \multicolumn{2}{|c|}{$1: 0,5$} & \multicolumn{2}{|c|}{$1: 1$} \\
\hline$Y$ & $\%$ & Yield & \multicolumn{2}{|c|}{39,0} & \multicolumn{2}{|c|}{70,4} \\
\hline$S_{B E T}$ & $\mathrm{~m}^{2} / \mathrm{g}$ & Specific surface & \multicolumn{2}{|c|}{890} & \multicolumn{2}{|c|}{777} \\
\hline$V_{\Sigma}$ & $\mathrm{cm}^{3} / \mathrm{g}$ & Total volume of pores & 0,58 & $100 \%$ & 0,42 & $100 \%$ \\
\hline$V_{m a}$ & $\mathrm{~cm}^{3} / \mathrm{g}$ & volume of macropores & 0,01 & $1,7 \%$ & 0,03 & $8,1 \%$ \\
\hline$V_{m e}$ & $\mathrm{~cm}^{3} / \mathrm{g}$ & volume of methopores & 0,25 & $43,1 \%$ & 0,09 & $21,6 \%$ \\
\hline$V_{m i}$ & $\mathrm{~cm}^{3} / \mathrm{g}$ & volume of micropores & 0,32 & $55,2 \%$ & 0,30 & $70,3 \%$ \\
\hline$V_{1 n m}$ & $\mathrm{~cm}^{3} / \mathrm{g}$ & volume of subnanopores & 0,23 & $39,7 \%$ & 0,25 & $59,2 \%$ \\
\hline$A_{\Phi}$ & $\mathrm{mg} / \mathrm{g}$ & Sorption of phenol & \multicolumn{2}{|r|}{120} & \multicolumn{2}{|c|}{200} \\
\hline$A_{P b}$ & $\mathrm{mmol} / \mathrm{g}$ & Sorption of $\mathrm{Pb}^{2+}$ & \multicolumn{2}{|c|}{-} & \multicolumn{2}{|c|}{0,7} \\
\hline$A_{M b}$ & $\mathrm{mg} / \mathrm{g}$ & Sorption of MB & \multicolumn{2}{|c|}{92} & \multicolumn{2}{|c|}{150} \\
\hline
\end{tabular}

Positive moments of our research process were energy saving, high yield and sufficient mechanical strength (MP $\geq 80 \%$ ) of the product. It is also important that during the conversion of the pyrolyzed chips into the adsorbents, tars are no eliminated (thus, the load on the environment is much less than when activating, for example, peat or coal).

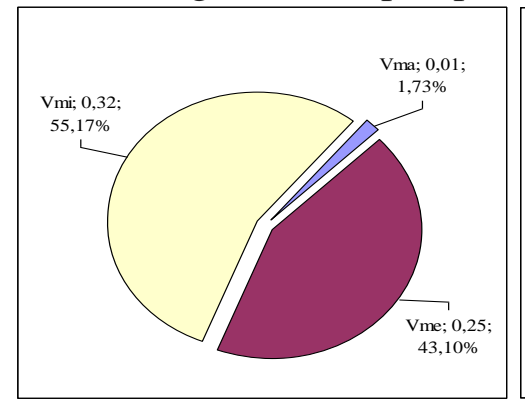

a

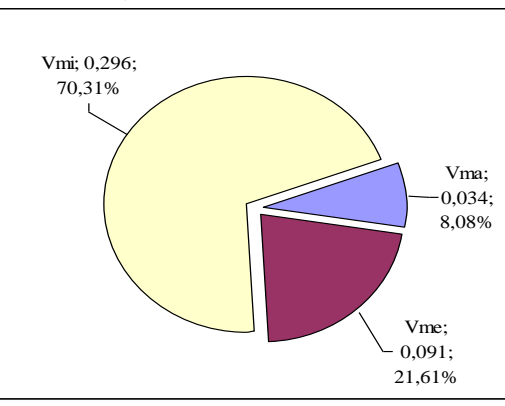

б

Figure. Distribution of pores in AC : a - from lignite; B - from the waste smoke production (CC)

\section{Conclusion}

The proposed approach allows to obtain the solid carbon sorbents from wood waste from the smoke industry by the method of alkaline activation. The process will result in a high yield (70-80\%) of the product with a developed specific surface and pore space, a high sorption capacity to some pollutants, and also a fractional composition of the particle size that is adapted to the technology of distillery production.

\section{Acknowledgments}

The authors express their sincere thanks to $\mathrm{PhD} Y \mathrm{Yu}$. Tamarkina for active participation in experimental work

\section{References}

[1] O.V. Kuzmin ta in. Pat. 103581 Ukrai'na, MPK C01V 31/08. Sposib vyrobnyctva porystyh vuglecevyh materialiv iz pirolizovanyh derevnyh vidhodiv / zajavnyk i patentovlasnyk NUHT. - №u201505455; zajav. 03.06.2015; opubl. 25.12.2015, Bjul. №24.

[2] O. Kuzmin, T.Shendrik,etc. Substantion of the conditions of obtaining PCM from PWW by chemical actuvation of $\mathrm{H}_{3} \mathrm{PO}_{4}$. "Ukrainian Food Journal", 2017, N6(1), pp.103-116. 